\title{
Influence of Curcumin Supplementation on Exercise-Induced Oxidative Stress
}

\author{
Babak Nakhostin Roohi, ${ }^{1, *}$ Arash Nasirvand Moradlou, ${ }^{2}$ and Lotfali Bolboli ${ }^{2}$ \\ ${ }^{1}$ Department of Exercise Physiology, Ardabil Branch, Islamic Azad University, Ardabil, Iran \\ ${ }^{2}$ Department of Exercise Physiology, Mohaghegh Ardabili University, Ardabil, Iran \\ "Corresponding author: Babak Nakhostin Roohi, Department of Exercise Physiology, Ardabil Branch, Islamic Azad University, Ardabil, Iran. E-mail: \\ b.nakhostinroohi@iauardabil.ac.ir
}

Received 2016 January 07; Revised 2016 May 14; Accepted 2016 May 24.

\begin{abstract}
Background: Polyphenols are a class of organic chemical compounds, with strong antioxidant capacity. This investigation evaluates the influences of one week curcumin supplementation on selected indices of oxidative stress after $14 \mathrm{~km}$ running in active healthy young males.

Objectives: The aim of this study was to investigate the effects of 1 week of curcumin supplementation on anti-oxidant markers. Methods: Subjects were randomized in a double blind, placebo-controlled fashion into two groups: Curcumin $(C)(n=11)$ and placebo $(P)(n=9)$. The subjects received supplementation $(90 \mathrm{mg})$ or placebo for 7 days before main trial. Then, subjects ran 14 $\mathrm{km}$. Total antioxidant capacity (TAC), reduced glutathione (GSH), and malondialdehyde (MDA-TBARS) were measured using spectrophotometer methods.

Results: There was a significant increase in TAC after supplementation $(\mathrm{P}<0.001, \mathrm{ES}=1.42)$, and immediately after exercise $(\mathrm{P}=0$. 008, $E S=1.12$ ) in $C$ group compared with the P group. MDA-TBARS was significantly lower in $C$ group compared with the $P$ group immediately after exercise $(P=0.022, E S=1.00)$. GSH significantly increased immediately, 24, and 48 hours after exercise compared with pre-exercise only in $\mathrm{C}$ group $(\mathrm{P}<0.05)$.

Conclusions: It is concluded one week oral supplementation of curcumin has positive effects on selected indices of oxidative stress possibly via promotion of antioxidant capacity.
\end{abstract}

Keywords: Curcumin, Total Antioxidant Capacity, Reduced Glutathione, Malondialdehyde

\section{Background}

Due to their molecular instability, in order to become stabilized, reactive species and free radicals promote oxidation reactions with other molecules, such as proteins, lipids, and DNA $(1,2)$. Oxidative stress as an imbalance between free radical production and the endogenous antioxidant defense system, predominantly results in accumulation of oxidative damage, activation of stress-sensitive signaling pathways and development of pathological conditions such as cardiovascular disease, metabolic syndrome, and insulin resistance (3).

According to the hormesis curve, exercise is able to modulate free radicals (4). On the one hand, reactive species and free radicals serve as stimulating signals of several genes which encode transcription factors, di [U+FB00] erentiation, and development as well as stimulating cell- cell adhesion, cell signaling, involvement in vasoregulation and fibroblast proliferation, and increased expression of antioxidant enzymes (5). On the other hand, as the other endpoint of the hormesis curve, intensive exercise or overtraining enhances the danger of disease and health hazards (6).
Our body has an elaborate network of antioxidants that act as a defense system neutralizing free radicals and reactive species. This process allows for the maintenance of homeostasis. Nevertheless, oxidative stress and impaired cellular function may occur if there is an increase in the body's oxidant concentrations, overwhelming the available antioxidants (7). Supplementation with antioxidants may help to attenuate the damage of the body induced by oxidative stress (8). Several studies have reported that supplementation with antioxidants is a good alternative for reducing the damage caused by exercise in athletes or non-athletes (9-12).

Curcumin is a hydroxycinnamic acid derivative and its structure contains two hydrophobic polyphenolic rings with two carbonyl groups. It is the main curcuminoid found in the spice turmeric, a plant alkaloid obtained from the ground rhizome of the perennial herb Curcuma longa. Curcumin is a part of the spice turmeric causing the yellow color of curry, which possesses anticancer, anti-in [U+FB02] ammatory, antioxidant, and antibacterial qualities (13). It has been used in the alternative medicine systems of India (Ayurvedic medicine) and Asia

Copyright (c) 2016, Sports Medicine Research Center. This is an open-access article distributed under the terms of the Creative Commons Attribution-NonCommercial 4.0 International License (http://creativecommons.org/licenses/by-nc/4.0/) which permits copy and redistribute the material just in noncommercial usages, provided the original work is properly cited. 
(traditional Chinese medicine) to treat gastrointestinal, pulmonary and liver disorders, wounds and sprains (14). Curcumin has been studied for multiple bio-functional activities, including anti-obesity (15), anti-inflammation (16), anti-cancer (17), anti-angiogenesis (18), anti-diabetes (19), hepato-protection (20), radio-protection (21), and chemopreventive activities (22). Recent research has shown curcumin to be a powerful antioxidant and it acts as a scavenger of the superoxide anion, the hydroxyl radical and nitrogen dioxide (23).

In recent years, a plethora of investigations can be observed in relation to the effect of different types of antioxidants on exercise-induced oxidative stress with controversial results. However, there are a few investigations to assess the influence of curcumin supplementation as an antioxidant on exercise-induced oxidative stress in humans. To the best of our knowledge, there is no study about the effect of 7 days supplementation of curcumin on exerciseinduced oxidative stress in humans.

\section{Objectives}

The purpose of this investigation was to assess the influences of one week curcumin supplementation on total antioxidant capacity (TAC), reduced glutathione (GSH) and lipid peroxidation (MDA) following an intensive training session.

\section{Methods}

\subsection{Participants}

In this study, twenty-two active, healthy males participated voluntarily. Each subject completed a pre-exercise health readiness questionnaire. The exclusion criteria for this study were: a) having history of surgical or medical procedures that might significantly influence the investigation results, including metabolic, renal, hepatic, cardiovascular or musculoskeletal diseases; b) using medication or being smokers that might have significantly affected the study outcome; c) using any nutritional supplements (i.e. vitamins, amino acids, creatine, protein drinks) in the 8 weeks before the beginning of the study; d) participating in another exercise program or ingesting other supplementation or drug two months before screening and participation in the study and e) having $\mathrm{VO}_{2}$ max between 45 $-55 \mathrm{~mL} / \mathrm{kg} / \mathrm{min}$. All Participants were informed of the purpose of the investigation and a written informed consent was obtained from the participation. The protocol of the study was approved by the university ethics committee in accordance with the Helsinki Declaration.

\subsection{Preliminary Measurements}

The Cooper 12-min run test was used to estimate $\mathrm{VO}_{2} \max (24)$. Participants warmed up for 10-min and then ran around the track for 12 minutes, and the distance covered was recorded. The participants were encouraged to push themselves as hard as they could. The formula used to calculate $\mathrm{VO}_{2}$ max is:

$(($ Total distance covered $\div 15)-133) \times 0.172))+33.3$

This test was performed almost two weeks before the main trial.

Furthermore, participants' fat\% was measured by body composition analyzer (Tanita, Japan).

\subsection{Experimental Design}

Participants were randomized in a double blind placebo-controlled study into two groups, curcumin (C) $(\mathrm{n}=11)$ and placebo $(\mathrm{P})(\mathrm{n}=11)$ (Table 1). They arrived at the laboratory after overnight fasting. A baseline blood sample was taken. Afterwards, subjects consumed 90 mg Curcumin (containing 10\% curcumin, 2\% curcuminoids without curcumin, $3.2 \%$ gum-ghatti, $0.27 \%$ citric acid, $54.53 \%$ dextrin and $30 \%$ maltose) or placebo (5\% tartrazine, 3.5\% gum-ghatti, $0.3 \%$ citric acid, $59.2 \%$ dextrin and $32 \%$ maltose) daily for 7 days. On the day of the test, participants attended the athletics arena after overnight fasting. After a second blood sampling, participants had a 10-min warm-up involving running at almost $50 \% \mathrm{VO}_{2} \max$ for 5 minutes and stretching for 5 -min. Then participants ran $14 \mathrm{~km}$ by their maximum efforts. They were allowed to consume water ad libitum throughout the trial. At the end of the trial, the intensity of exercise was evaluated by Borg scale (25). Blood samples were taken immediately, 24 hours, and 48 hours after exercise. Two participants of $\mathrm{P}$ group could not finish the trial and had to be withdrawn.

Table 1. Subjects' Characteristics (Mean \pm SD)

\begin{tabular}{|c|c|c|}
\hline & $\operatorname{Curcumin}(\mathbf{n}=\mathbf{1 1})$ & $\operatorname{Placebo}(\mathbf{n}=9)$ \\
\hline Age, $y$ & $25.6 \pm 2.7$ & $24.1 \pm 1.7$ \\
\hline Height, cm & $179.3 \pm 7.7$ & $178.9 \pm 4.6$ \\
\hline Weight, kg & $68.8 \pm 18.8$ & $76.3 \pm 8.7$ \\
\hline Body mass index, kg. m-2 & $22.9 \pm 2.5$ & $23.7 \pm 2.5$ \\
\hline $\mathrm{VO}_{2} \mathrm{max}, \mathrm{mL} \cdot \mathrm{Kg}^{-1} \cdot \mathrm{min}^{-1}$ & $48.4 \pm 3.9$ & $50.3 \pm 4.9$ \\
\hline Fat, \% & $11.2 \pm 3.9$ & $12.1 \pm 3.6$ \\
\hline Running record (minute) & $80.8 \pm 5.7$ & $86.4 \pm 7.6$ \\
\hline Borg scale & $7.8 \pm 0.8$ & $7.8 \pm 0.7$ \\
\hline
\end{tabular}




\subsection{Blood Sampling and Analysis}

Almost $5 \mathrm{ml}$ of blood was withdrawn at each time point. Two milliliters of blood were located in heparinized tubes and centrifuged at $3000 \mathrm{rpm}$ for 10 minutes at $4^{\circ} \mathrm{C}$. Plasma was transferred to micro tubes and stored at $-80^{\circ} \mathrm{C}$ for later analysis. The remainder of the blood was allowed to clot and centrifuged at $5000 \mathrm{rpm}$ for $15 \mathrm{~min}$ utes. Obtained serum in $0.2 \mathrm{~mL}$ volumes was stored at $80^{\circ} \mathrm{C}$ until analysis. The Varga method was used to analyze TAC (26). This method is based on the reduction of ferric tripyridyltriazine (Fe (III)-TPTZ) complex to the ferrous tripyridyltriazine (Fe (II)-TPTZ) by a reductant of low pH. Fe (II)-TPTZ has an intensive blue color and can be monitored at $593 \mathrm{~nm}$. Lipid peroxidation was measured via thiobarbituric acid-reactive substance (MDA-TBARS) level (27). In this method, the sample was homogenized with aqueous trichloroacetic acid in the presence of hexane and BTH, and the homogenate was centrifuged. Hexane added before blending was effective for reducing lipid peroxidation; BHT showed an outstanding antioxidant activity. Full protection against autoxidation was assured when BHT was added to the sample before the homogenization process. Following the reaction with thiobarbituric acid reagent, MDA was directly quantified (at $521 \mathrm{~nm}$ ) on the basis of the third-derivative absorption spectrum of the pink complex formed.

GSH was also measured by the Ellman method (28). In this method, 5, 5'-dithio-bis-(2-nitrobenzoic acid), also known as DTNB, as a versatile water-soluble compound was used to measure free sulfhydryl groups in solution. A solution of this compound produces a measurable yellowcolored product when it reacts with sulfhydryls. The TNB2 is quantified in a spectrophotometer by measuring the absorbance of visible light at $412 \mathrm{~nm}$, using an extinction coefficient of $14,150 \mathrm{M}^{-1} \mathrm{~cm}^{-1}$.

\subsection{Statistical Analysis}

All data are presented as mean \pm SEM, and statistical significance was set at the $\mathrm{P}<0.05$ level. Subject characteristics and running records were compared under two groups using independent samples t-test (Table 1). The data, which contained multiple time points during the main trial, were analyzed using mixed-model repeated-measures ANOVA. Mauchly's test was consulted and Greenhouse-Geisser correction was applied if the assumption of sphericity was violated. If a significant $P$ value was identified for the main effect of time (time of sample), multiple pairwise comparisons were made using the Bonferroni confidence interval adjustment. Moreover, the dependent variable data in multiple time points between two groups were compared using independent samples t-test.

\section{Results}

\subsection{Participants' Characteristics}

The characteristics of participants, including age, height, BMI, fat\% and preliminary $\mathrm{VO}_{2}$ max, as well as running records and Borg scale results are summarized in There There were no significant differences between physical characteristics of both groups $(\mathrm{P}<0.05)$. Furthermore, there was no significant differences in Borg scales and running records between groups $(\mathrm{P}<0.05)$.

\subsection{Total Antioxidant Capacity}

Baseline resting serum TAC was not different between groups ( $\mathrm{P}>0.05)$. TAC significantly increased only in $\mathrm{C}$ group after 7 day supplementation compared with baseline $(\mathrm{P}<0.05)$ and $\mathrm{P}$ group $(\mathrm{P}<0.001, \mathrm{ES}=1.42)$. TAC significantly increased immediately after exercise in both groups compared with baseline. Furthermore, It was enhanced in $C$ group immediately after exercise compared with the $\mathrm{P}$ group $(P=0.008, E F=1.12)$. TAC was significantly higher in both groups, 24 hours and 48 hours after exercise compared with baseline $(\mathrm{P}=0.022)$ (Figure 1$)$.

Figure 1. TAC Concentrations in Plasma

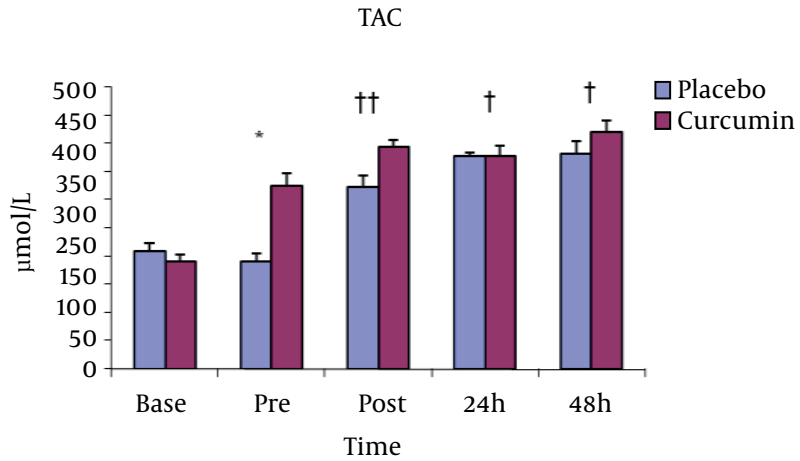

Values represent means \pm SEM. ${ }^{*}$ shows significant increase in $C$ group compared with $\mathrm{P}$ group and baseline $(\mathrm{P}<0.05)$. $\dagger$ i demonstrates a significant increase in $\mathrm{C}$ group compared with $\mathrm{P}$ group and both groups compared with baseline $(\mathrm{P}<0.05)$. $\dagger$ demonstrates a significant increase in both groups compared with baseline $(\mathrm{P}<$ 0.05).

\subsection{Lipid Peroxidation}

Baseline resting serum MDA-TBARS was not different between groups ( $\mathrm{P}>0.05)$. MDA-TBARS significantly increased immediately, 24 hours, and 48 hours after exercise in both groups compared with baseline $(\mathrm{P}<0.05)$. Furthermore, MDA-TBARS was significantly lower in C group compared with the $\mathrm{P}$ group immediately after exercise $(\mathrm{P}=0$. 022, $\mathrm{ES}=1.00$ ) (Figure 2). 
Figure 2. MDA-TBARS Concentrations in Serum

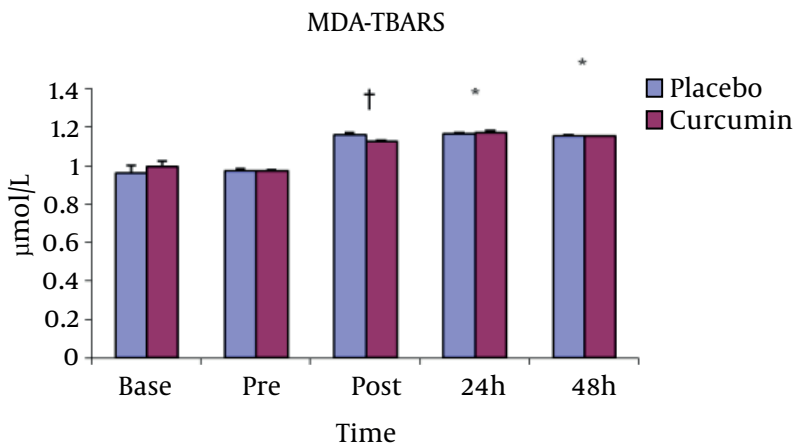

Values represent means \pm SEM. †shows significant increase in both groups compared with baseline as well as increase in P group compared with $\mathrm{C}$ group $(\mathrm{P}<0.05)$. demonstrates significant enhancement in both groups compared with baseline ( $\mathrm{P}$ $<0.05)$.

\subsection{Reduced Glutathione}

Baseline resting serum GSH was not different between groups ( $\mathrm{P}>0.05)$. GSH significantly increased immediately, 24 hours, and 48 hours after exercise in C groups compared with baseline $(\mathrm{P}<0.05)$. Furthermore, GSH was significantly higher in P group compared with baseline just in 24 hours after exercise $(\mathrm{P}<0.05)$ (Figure 2$)$.

\section{Discussion}

The findings of this study suggest that curcumin supplementation may increase antioxidant capacity and alleviate markers of oxidative stress following intensive endurance-like exercise.

In the present study, similar to our previous studies $(10,29) ; 14 \mathrm{~km}$ running has been able to induce oxidative stress after exercise. It can be seen in Figure 2 that MDATBARS concentration as a marker of lipid peroxidation significantly increased after exercise in both groups, immediately, 24, and 48 hours after exercise, demonstrating 14 $\mathrm{km}$ continuous running in our subjects to lead oxidative stress.

Moreover, the present study demonstrates an increase in plasma TAC level, 7 days after supplementation just in $C$ group showing the possible effect of curcumin supplementation as an antioxidant (Figure 1). Curcumin is a component of the spice turmeric responsible for the yellow color of curry, which has been known to possess antioxidant property (13). Therefore, its supplementation could be responsible for TAC promotion in $\mathrm{C}$ group. Increase in TAC following exercise was also reported $(2,30)$. TAC significantly increased immediately, 24 hours, and 48 hours after exercise in both groups showing the effect of exercise on TAC. It seems promotion in the activity of antioxidant enzymes such as superoxide dismutase (SOD), and glutathione peroxidase (GPX) is responsible for TAC enhancement after exercise. For example, it was demonstrated that SOD concentration increases after physical exhaustion (31, 32). A similar effect was observed in case of GPX (32).

Furthermore, immediately after exercise, TAC was significantly higher in $\mathrm{C}$ group compared with $\mathrm{P}$ group, indicating the possible effects of curcumin supplementation. Increase in TAC may be owing to within the group GSH promotion in C group (Figure 3). GSH is an antioxidant and curcumin supplementation may lead to increase in GSH contents in the supplemented group (Figure 3). According to GHS GHS concentrations have increased in C group compared with pre-exercise immediately, 24 hours, and 48 hours after exercise. Curcumin supplementation is a possible reason for GSH promotion, but the mechanism of promotion is not clear.

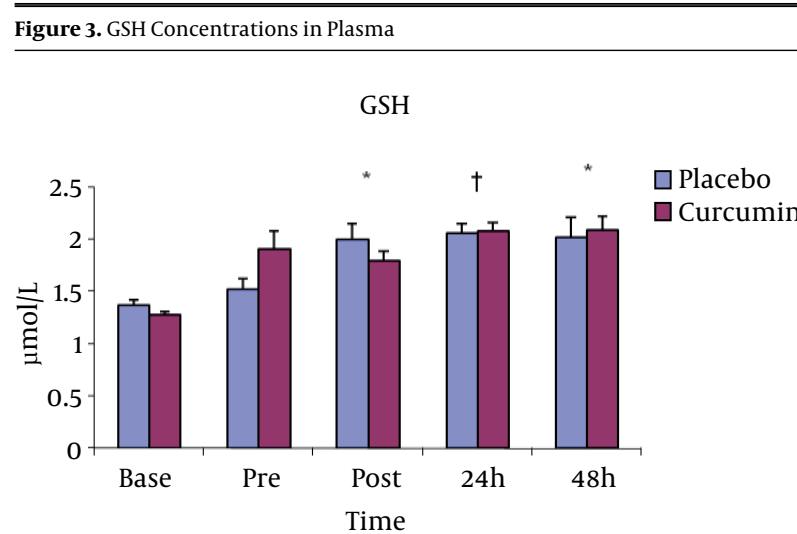

Values represent means \pm SEM. †shows significant increase in both groups com pared with baseline $(\mathrm{P}<0.05) .{ }^{*}$ demonstrates significant enhancement just in $\mathrm{C}$ group compared with baseline $(\mathrm{P}<0.05)$.

In our previous works, we considered supplementation with some antioxidants such as L-carnitine and MSM in the similar supplementation pattern had been able to attenuate exercise-induced oxidative stress $(11,29)$. Some studies have demonstrated ROS scavenging activity of curcumin (33-35). In the present study, it seems one week curcumin supplementation has been able to increase antioxidant capacity in $\mathrm{C}$ group compared with the P group (Figure 1). The ROS scavenging activity of curcumin can result from either from the $\mathrm{CH}_{2}$ group of the $\beta$-diketonemoiety or the phenolic $\mathrm{OH}$ groups (36). Particularly, a number of investigations demonstrated that the phenolic $\mathrm{OH}$ groups of curcumin are necessary for the ROS scavenging activity and that the existence of the methoxy groups raise the activity more $(34,37)$. In agreement with our study, Takahashi showed acute curcumin supplementation could alleviate 
oxidative stress in untrained men after 60 minutes running or walking at $65 \%$ of their $\mathrm{VO}_{2} \max (38)$.

In conclusion, the present study indicates that acute intensive bout of exercise leads oxidative stress in healthy untrained men. One week oral supplementation of curcumin has some alleviating effects on lipid peroxidation and may augment intracellular antioxidant system. Thus, it seems both athletes during especial preparation and ordinary people before a strenuous bout of exercise can use this supplementation to inhibit high level oxidative stress. Nonetheless, the precise mechanism of curcumin to attenuate the oxidative stress indices is not perfectly established and more studies should be performed.

\section{Acknowledgments}

We are grateful of technical support of Ardabil branch, Islamic Azad University staff.

\section{Footnotes}

Authors' Contribution: Babak Nakhostin-Roohi: study concept and design, acquisition of data, analysis and interpretation of data, drafting of the manuscript, critical revision of the manuscript for important intellectual content, statistical analysis, administrative, technical, and material support and study supervision; Arash Nasirvand Moradlou: study concept and design, acquisition of data and analysis and interpretation of data; Lotfali Bolboli: study concept and design, administrative, technical, and material support and study supervision.

Funding/Support: This study was supported in part by grant from Mohagheghe-Ardabili University as a MSc thesis.

\section{References}

1. Freitas M, Gomes A, Porto G, Fernandes E. Nickel induces oxidative burst, NF-kappaB activation and interleukin-8 production in human neutrophils. J Biol Inorg Chem. 2010;15(8):1275-83. doi:10.1007/s00775010-0685-3. [PubMed: 20632048].

2. Fisher-Wellman K, Bloomer RJ. Acute exercise and oxidative stress: a 30 year history. Dyn Med. 2009;8:1. doi: 10.1186/1476-5918-8-1. [PubMed: 19144121].

3. Yavari A, Javadi M, Mirmiran P, Bahadoran Z. Exercise-induced oxidative stress and dietary antioxidants. Asian J Sports Med. 2015;6(1):14898. doi: 10.5812/asjsm.24898. [PubMed: 25883776].

4. Radak Z, Chung HY, Koltai E, Taylor AW, Goto S. Exercise, oxidative stress and hormesis. Ageing Res Rev. 2008;7(1):34-42. doi: 10.1016/j.arr.2007.04.004. [PubMed: 17869589].

5. Powers SK, Jackson MJ. Exercise-induced oxidative stress: cellular mechanisms and impact on muscle force production. Physiol Rev. 2008;88(4):1243-76. doi: 10.1152/physrev.00031.2007. [PubMed: $18923182]$.
6. Ogonovszky H, Berkes I, Kumagai S, Kaneko T, Tahara S, Goto S, et al. The effects of moderate-, strenuous- and over-training on oxidative stress markers, DNA repair, and memory, in rat brain. Neurochem Int. 2005;46(8):635-40. doi: 10.1016/j.neuint.2005.02.009. [PubMed: 15863241].

7. Powers SK, DeRuisseau KC, Quindry J, Hamilton KL. Dietary antioxidants and exercise. J Sports Sci. 2004;22(1):81-94. doi: 10.1080/0264041031000140563. [PubMed: 14971435].

8. Hosseinzadeh H, Sajadi Tabassi SA, Milani Moghadam N, Rashedinia M, Mehri S. Antioxidant Activity of Pistacia vera Fruits, Leaves and Gum Extracts. Iran J Pharm Res. 2012;11(3):879-87. [PubMed: 24250515].

9. Nakhostin-Roohi B, Babaei P, Rahmani-Nia F, Bohlooli S. Effect of vitamin $C$ supplementation on lipid peroxidation, muscle damage and inflammation after 30-min exercise at 75\% VO2max. J Sports Med Phys Fitness. 2008;48(2):217-24. [PubMed: 18427418].

10. Nakhostin-Roohi B, Barmaki S, Khoshkhahesh F, Bohlooli S. Effect of chronic supplementation with methylsulfonylmethane on oxidative stress following acute exercise in untrained healthy men. J Pharm Pharmacol. 2011;63(10):1290-4. doi: 10.1111/j.2042-7158.2011.01314.x. [PubMed: 21899544].

11. Nakhostin-Roohi B, Niknam Z, Vaezi N, Mohammadi S, Bohlooli S. Effect of single dose administration of methylsulfonylmethane on oxidative stress following acute exhaustive exercise. Iran J Pharm Res. 2013;12(4):845-53. [PubMed: 24523764].

12. Bohlooli S, Barmaki S, Khoshkhahesh F, Nakhostin-Roohi B. The effect of spinach supplementation on exercise-induced oxidative stress. $J$ Sports Med Phys Fitness. 2015;55(6):609-14. [PubMed: 24921623].

13. Avci G, Kadioglu H, Sehirli AO, Bozkurt S, Guclu O, Arslan E, et al. Curcumin protects against ischemia/reperfusion injury in rat skeletal muscle. J Surg Res. 2012;172(1):39-46. doi: 10.1016/j.jss.2011.08.021. [PubMed: 22079841].

14. Aggarwal BB, Sundaram C, Malani N, Ichikawa H. Curcumin: the Indian solid gold. Adv Exp Med Biol. 2007;595:1-75. doi: 10.1007/978-0387-46401-5_1. [PubMed: 17569205].

15. Wang S, Moustaid-Moussa N, Chen L, Mo H, Shastri A, Su R, et al. Novel insights of dietary polyphenols and obesity. J Nutr Biochem. 2014;25(1):1-18. doi: 10.1016/j.jnutbio.2013.09.001. [PubMed: 24314860].

16. Aggarwal BB, Gupta SC, Sung B. Curcumin: an orally bioavailable blocker of TNF and other pro-inflammatory biomarkers. Br J Pharmacol. 2013;169(8):1672-92. doi:10.1111/bph.12131. [PubMed: 23425071].

17. Gao Y, Shi Q, Xu S, Du C, Liang L, Wu K, et al. Curcumin promotes KLF5 proteasome degradation through downregulating YAP/TAZ in bladder cancer cells. Int J Mol Sci. 2014;15(9):15173-87. doi: 10.3390/ijms150915173. [PubMed: 25170806].

18. Ding Q, Niu T, Yang Y, Guo Q, Luo F, Qian Z. Preparation of curcuminloaded poly(ester amine) nanoparticles for the treatment of antiangiogenesis. J Biomed Nanotechnol. 2014;10(4):632-41. [PubMed: 24734515].

19. Soetikno V, Sari FR, Sukumaran V, Lakshmanan AP, Harima M, Suzuki K, et al. Curcumin decreases renal triglyceride accumulation through AMPK-SREBP signaling pathway in streptozotocininduced type 1 diabetic rats. J Nutr Biochem. 2013;24(5):796-802. doi: 10.1016/j.jnutbio.2012.04.013. [PubMed: 22898567].

20. Wang ME, Chen YC, Chen IS, Hsieh SC, Chen SS, Chiu CH. Curcumin protects against thioacetamide-induced hepatic fibrosis by attenuating the inflammatory response and inducing apoptosis of damaged hepatocytes. J Nutr Biochem. 2012;23(10):1352-66. doi: 10.1016/j.jnutbio.2011.08.004. [PubMed: 22221674].

21. Tawfik SS, Abouelella AM, Shahein YE. Curcumin protection activities against gamma-rays-induced molecular and biochemical lesions. BMC Res Notes. 2013;6:375. doi: 10.1186/1756-0500-6-375. [PubMed: 24053347].

22. Ramamoorthi G, Sivalingam N. Molecular mechanism of TGF-beta signaling pathway in colon carcinogenesis and status of curcumin as chemopreventive strategy. Tumour Biol. 2014;35(8):7295-305. doi: 10.1007/s13277-014-1840-1. [PubMed: 24668546]. 
23. Daniel S, Limson JL, Dairam A, Watkins GM, Daya S. Through metal binding, curcumin protects against lead- and cadmium-induced lipid peroxidation in rat brain homogenates and against leadinduced tissue damage in rat brain. J Inorg Biochem. 2004;98(2):26675. [PubMed: 14729307]

24. Cooper S, Helmstetter CE. Chromosome replication and the division cycle of Escherichia coli B/r. J Mol Biol. 1968;31(3):519-40. [PubMed: 4866337].

25. Borg G, Linderholm H. Exercise performance and perceived exertion in patients with coronary insufficiency, arterial hypertension and vasoregulatory asthenia1. Acta Medica Scandinavica. 1970;187(1-6):17-26. doi: 10.1111/j.0954-6820.1970.tb02901.x.

26. Varga IS, Matkovics B. Comparative study of plasma antioxidant status in normal and pathological cases. Pathophysiol. 1998;5:77. doi: 10.1016/S0928-4680(98)80581-6.

27. Botsoglou NA, Fletouris DJ, Papageorgiou GE, Vassilopoulos VN, Mantis AJ, Trakatellis AG. Rapid, sensitive, and specific thiobarbituric acid method for measuring lipid peroxidation in animal tissue, food, and feedstuff samples. J Agri Food Chem. 1994;42(9):1931-7.

28. Ellman GL. Tissue sulfhydryl groups. Arch Biochem Biophysics. 1959;82(1):70-7.

29. Parandak K, Arazi H, Khoshkhahesh F, Nakhostin-Roohi B. The effect of two-week L-carnitine supplementation on exercise-induced oxidative stress and muscle damage. Asian J Sports Med. 2014;5(2):123-8. [PubMed: 25834706].

30. Barmaki S, Bohlooli S, Khoshkhahesh F, Nakhostin-Roohi B. Effect of methylsulfonylmethane supplementation on exercise - Induced muscle damage and total antioxidant capacity. J Sports Med Phys Fitness. 2012;52(2):170-4. [PubMed: 22525653].

31. Di Massimo C, Scarpelli P, Penco M, Tozzi-Ciancarelli MG. Possible involvement of plasma antioxidant defences in training-associated decrease of platelet responsiveness in humans. Eur J Appl Phys- iol. 2004;91(4):406-12. doi: 10.1007/s00421-003-0998-9. [PubMed: 14624297].

32. Schneider CD, Barp J, Ribeiro JL, Bello-Klein A, Oliveira AR. Oxidative stress after three different intensities of running. Can J Appl Physiol. 2005;30(6):723-34. [PubMed:16485522].

33. Barzegar A, Moosavi-Movahedi AA. Intracellular ROS protection efficiency and free radical-scavenging activity of curcumin. PLoS One. 2011;6(10):26012. doi: 10.1371/journal.pone.0026012. [PubMed: 22016801].

34. Ravindran J, Subbaraju GV, Ramani MV, Sung B, Aggarwal BB. Bisdemethylcurcumin and structurally related hispolon analogues of curcumin exhibit enhanced prooxidant, anti-proliferative and antiinflammatory activities in vitro. Biochem Pharmacol. 2010;79(11):165866. doi:10.1016/j.bcp.2010.01.033. [PubMed: 20138025].

35. Zhao SG, Li Q, Liu ZX, Wang JJ, Wang XX, Qin M, et al. Curcumin attenuates insulin resistance in hepatocytes by inducing $\mathrm{Nrf} 2 \mathrm{nu}-$ clear translocation. Hepatogastroenterology. 2011;58(112):2106-11. doi: 10.5754/hge11219. [PubMed: 22024084].

36. Anand P, Thomas SG, Kunnumakkara AB, Sundaram C, Harikumar $\mathrm{KB}$, Sung B, et al. Biological activities of curcumin and its analogues (Congeners) made by man and Mother Nature. Biochem Pharmacol. 2008;76(11):1590-611. doi: 10.1016/j.bcp.2008.08.008. [PubMed: 18775680].

37. Singh U, Barik A, Singh BG, Priyadarsini KI. Reactions of reactive oxygen species (ROS) with curcumin analogues: Structureactivity relationship. Free Radic Res. 2011;45(3):317-25. doi: 10.3109/10715762.2010.532493. [PubMed: 21034358].

38. Takahashi M, Suzuki K, Kim HK, Otsuka Y, Imaizumi A, Miyashita M, et al. Effects of curcumin supplementation on exercise-induced oxidative stress in humans. Int J Sports Med. 2014;35(6):469-75. doi: 10.1055/s-0033-1357185. [PubMed: 24165958]. 